\title{
Left ventricular injury: Beware the wire
}

Lyle Dershowitz, BA, ${ }^{\mathrm{a}}$ Mariusz Wolbinski, MD, ${ }^{\mathrm{b}}$ Vinayak Bapat, MD, ${ }^{\mathrm{b}}$ Isaac George, MD, ${ }^{\mathrm{b}}$ and Susheel Kodali, MD, ${ }^{\mathrm{c}}$ New York, NY

From the a Columbia University Medical Center, Vagelos College of Physicians and Surgeons, New York, NY; ${ }^{\mathrm{b}}$ Division of Cardiothoracic Surgery, New York Presbyterian Hospital, Columbia University Medical Center, New York, NY; and ${ }^{c}$ Division of Interventional Cardiology, Structural Heart and Valve Center, New York Presbyterian Hospital-Columbia University Medical Center, New York, NY.

Disclosures: Dr George is a consultant for Edwards Lifesciences and Medtronic, and a speaker for Boston Scientific. All other authors reported no conflicts of interest.

The Journal policy requires editors and reviewers to disclose conflicts of interest and to decline handling or reviewing manuscripts for which they may have a conflict of interest. The editors and reviewers of this article have no conflicts of interest.

Received for publication Feb 3, 2020; revisions received Feb 3, 2020; accepted for publication Feb 25, 2020; available ahead of print March 8, 2020.

Address for reprints: Isaac George, MD, 177 Fort Washington Ave, 7GN-435, New York, NY 10032 (E-mail: 1bd2123@cumc.columbia.edu).

JTCVS Techniques 2020;3:126-9

2666-2507

Copyright (C) 2020 The Authors. Published by Elsevier Inc. on behalf of The American Association for Thoracic Surgery. This is an open access article under the CC BY-NC-ND license (http://creativecommons.org/licenses/bync-nd/4.0/).

https://doi.org/10.1016/j.xjtc.2020.02.019

Videos clip is available online.

Transcatheter mitral valve-in-valve has emerged as a viable alternative to repeat surgical mitral valve replacement for high-risk patients with structural valvular degeneration. ${ }^{1}$ However, wire perforation and left ventricular (LV) pseudoaneurysm have been recognized as rare but dangerous complications. ${ }^{2,3}$ Although surgery remains the gold standard treatment for LV pseudoaneurysm, recent advances in transcatheter technology have made percutaneous closure an acceptable alternative, especially for patients at high surgical risk. ${ }^{4,5}$

Despite the recognized co-incidence of LV injury and bioprosthetic valvular degeneration in high-risk patients, to our knowledge no concomitant transcatheter LV pseudoaneurysm closure and mitral valve-in-valve has ever been reported. We describe the case of a patient with mitral structural valvular degeneration who presented to our institution after a failed transcatheter mitral valve-in-valve complicated by LV wire perforation.

\section{CASE PRESENTATION}

A 77-year-old woman with a history of surgical aortic (\#19 Magna Ease; Edwards Lifesciences, Irvine, Calif) and mitral (\#25 Biocor Epic; St Jude, Abbott, Minneapolis, Minn) valve replacements 4 years ago presented to an

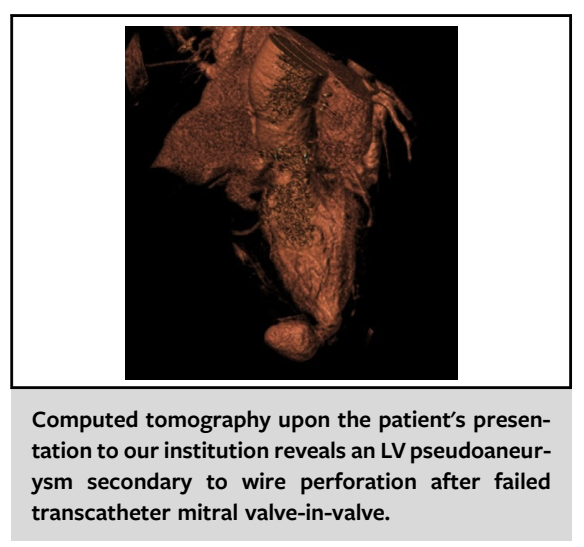

\begin{abstract}
CENTRAL MESSAGE
We report the first combined

transcatheter LV pseudoaneur-

ysm plug and transcatheter

mitral valve-in-valve and show its

efficacy in the growing cohort of

patients with structural valvular

degeneration and LV

pseudoaneurysm.
\end{abstract}

See Commentaries on pages 130 and 131.

outside institution with chest pain and shortness of breath. Transesophageal echocardiogram at that presentation showed significant central mitral regurgitation. The patient subsequently underwent attempted transcatheter mitral valve-in-valve, but the procedure was complicated by iatrogenic apical LV wire perforation and acute pericardial tamponade. The procedure was converted to an emergency open surgery without valve replacement, with epicardial hemostasis and suture closure of the LV injury.

In February 2019, the patient presented to our valve team with dyspnea on minimal exertion and New York Heart Association Class III congestive heart failure. Other comorbidities included severe transfusion-dependent hemolytic anemia, chronic steroid use, atrial fibrillation, arthritis, osteoporosis, and hypertension. Transesophageal echocardiogram on presentation showed preserved LV systolic function, mildly dilated right ventricle with mild- 


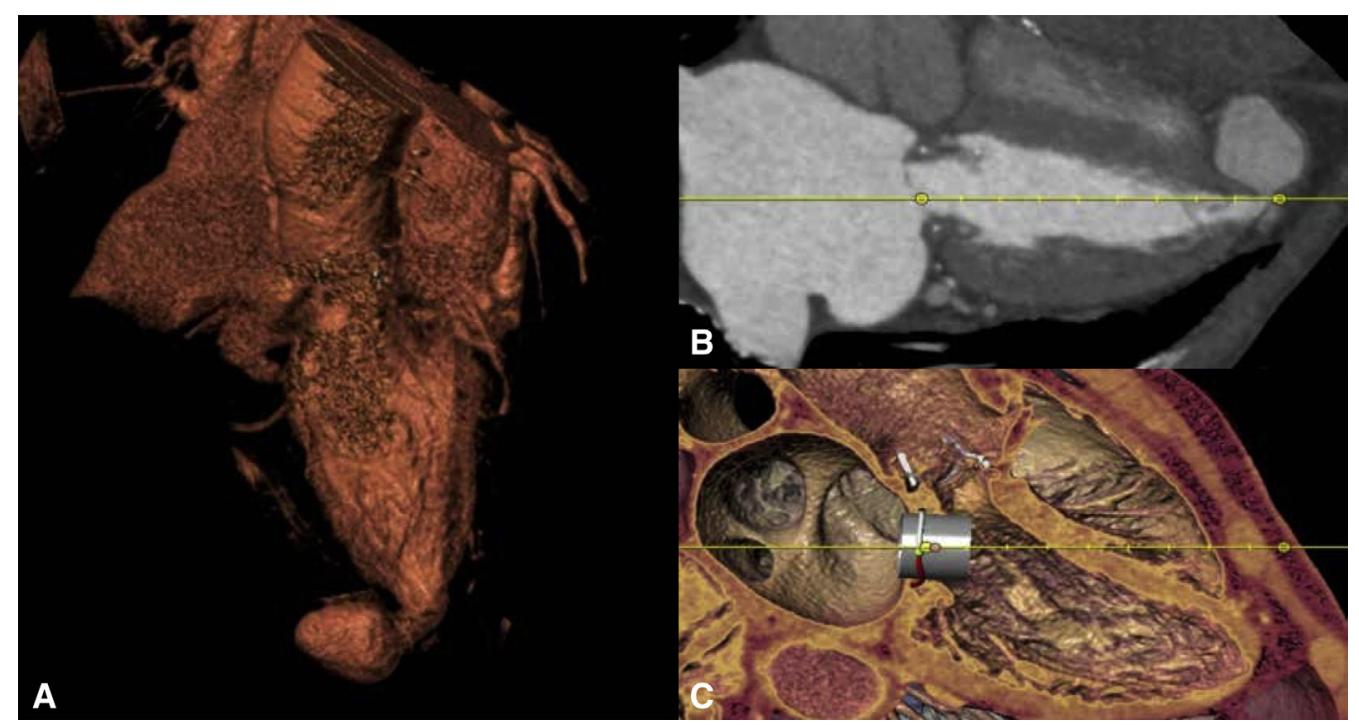

FIGURE 1. Preprocedural computed tomography (CT) demonstrating LV apical aneurysm. A and B, CT reveals an LV pseudoaneurysm arising from the apex with a $0.4-\mathrm{cm}$ narrow neck abutting the right ventricle. C, A virtual valve is placed in the mitral position for analysis of $\mathrm{LV}$ outflow tract obstruction demonstrating adequate clearance.

moderate dysfunction, tethered tricuspid valve with severe regurgitation, and degenerative mitral bioprosthesis with severe mitral regurgitation. Computed tomography angiogram revealed the presence of an apical postoperative LV pseudoaneurysm measuring $2.5 \times 2.6 \times 2.3 \mathrm{~cm}$ with a narrow 0.4-cm neck (Figure 1). Because of the patient's severely elevated Society of Thoracic Surgeons score for mitral valve replacement of $22 \%$ and 2 previous sternotomies, the decision was made to address the mitral regurgitation and LV pseudoaneurysm concomitantly with a transcatheter approach with surgical backup, with the understanding that durability may be limited and a surgical repair would be necessary in the future. Despite the elevated risk, hospice was not considered because we thought she was sufficiently healthy and active to benefit from intervention. The patient underwent transfemoral transcatheter mitral valve-in-valve with a 23-mm Edwards Sapien 3 (Edwards Lifesciences) valve and LV pseudoaneurysm closure with an Amplatzer Vascular Plug II (Abbott) in April of 2019.

In the operating room, the LV pseudoaneurysm closure was performed with a retrograde approach. An AL1 catheter from the left femoral artery access sheath was advanced across the aortic valve. A 5F MPA guide (Cordis Corporation, Santa Clara, Calif) easily cannulated the pseudoaneurysm, and an Amplatzer Vascular Plug \#6 was positioned within the defect (Videos 1 and 2). Consideration was given to placing coils in the defect, but given the potential for embolization, an Amplatzer alone was thought to be the most stable option. Angiography confirmed near complete closure of the neck of the pseudoaneurysm, the device was successfully deployed, and the guide was removed (Video 2).
Attention then turned to the mitral valve. By using a trans-septal approach, the mitral valve was crossed and a Confida wire was exchanged and positioned within the LV. The Edwards Sapien 3 valve was advanced and positioned with fluoroscopic and transesophageal echocardiogram guidance. The valve was then successfully deployed with rapid ventricular pacing (Videos 3 and 4). By the end of the procedure, imaging confirmed only trivial intervalvular mitral regurgitation with no central regurgitation.

After the procedure, the patient progressed well and was ready for discharge on hospital day 5. Echocardiography at 1-month follow-up revealed proper placement of the Sapien 3 in the mitral position, absence of central mitral regurgitation, and only trace paravalvular flow. Computed tomography confirmed no communication between the stable aneurysmal sac and the LV (Figure 2). At 6 months' follow-up, the patient was euvolemic and continued to report significant improvement with an ability to walk more than 1 mile on most days. The patient provided informed consent for the publication of the study data.

\section{CONCLUSIONS}

LV injury is a rare and important complication of transcatheter mitral valve-in-valve due to wire interventions., However, an aging population and a significant shift from mechanical to bioprosthetic mitral valve replacement stand to increase the number of patients with structural valvular degeneration indicated for transcatheter mitral valve-invalve. ${ }^{3}$ This expansion of valve-in-valve procedures may increase the incidence of postoperative LV injury in highrisk patients. We report the first concomitant transcatheter LV pseudoaneurysm closure and mitral valve-in-valve and 


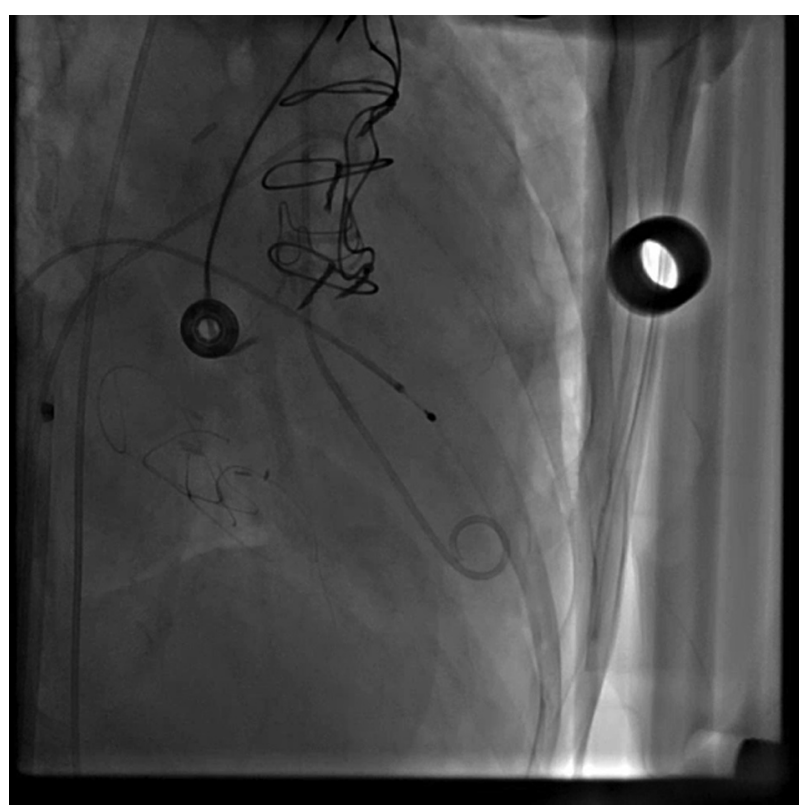

VIDEO 1. Intraprocedural fluoroscopy depicting LV pseudoaneurysm. Video available at: https://www.jtcvs.org/article/S2666-2507(20)30125-5/ fulltext.

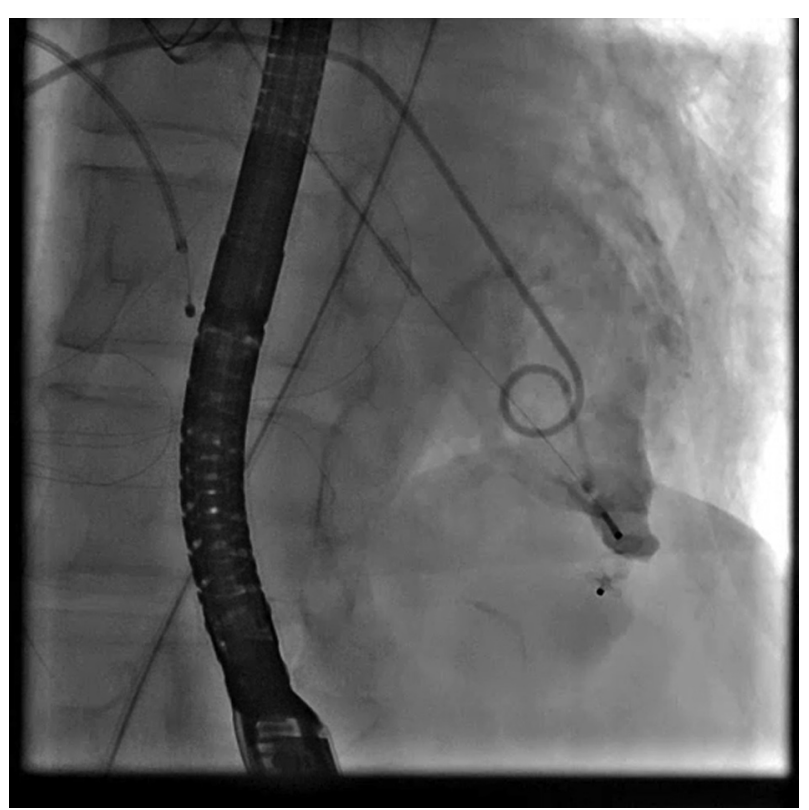

VIDEO 2. Positioning the Amplatzer (Abbott, Chicago, Ill) vascular plug in the narrow $0.4 \mathrm{~cm}$ neck of the LV pseudoaneurysm. Video available at: https://www.jtcvs.org/article/S2666-2507(20)30125-5/fulltext.

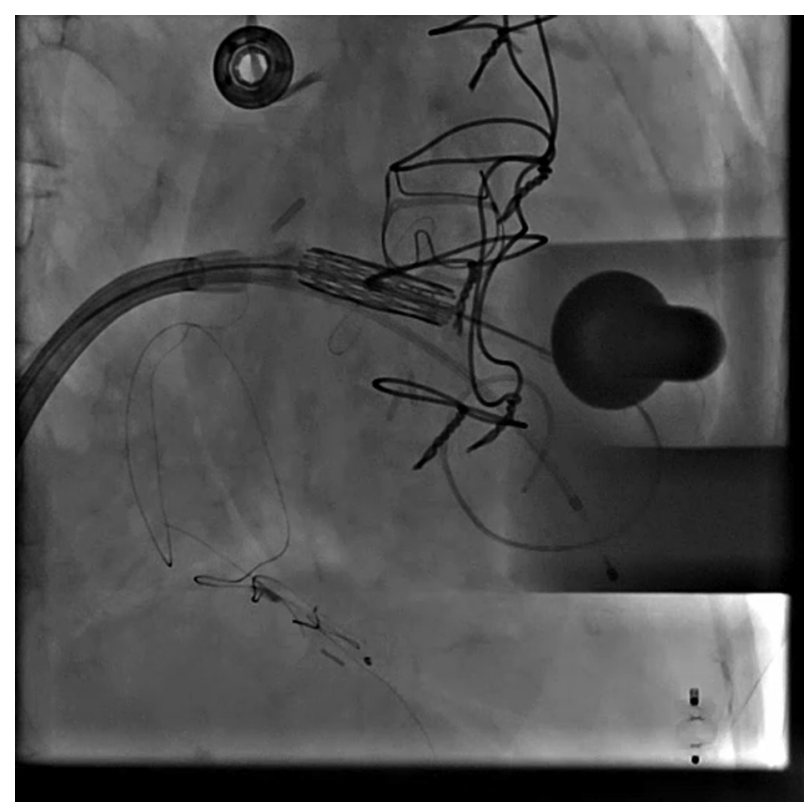

VIDEO 3. Deploying the Edwards Sapien 3 valve-in-valve under rapid ventricular pacing after successful closure of the LV pseudoaneurysm. Video available at: https://www.jtcvs.org/article/S2666-2507(20)30125-5/ fulltext.

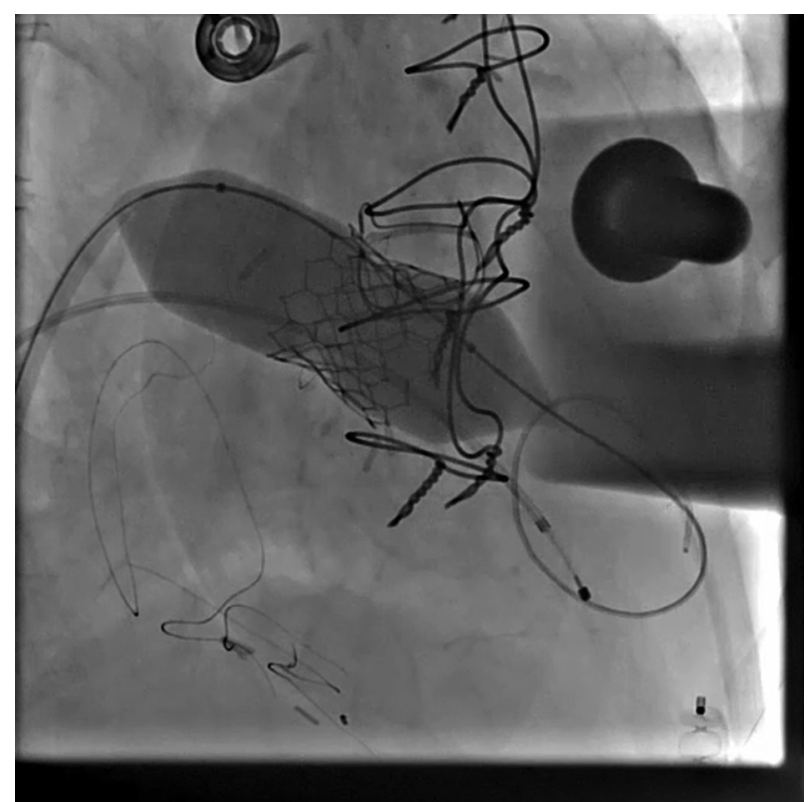

VIDEO 4. Aligning the Edwards Sapien 3 valve-in-valve after successful closure of the LV pseudoaneurysm. Video available at: https://www.jtcvs. org/article/S2666-2507(20)30125-5/fulltext. 


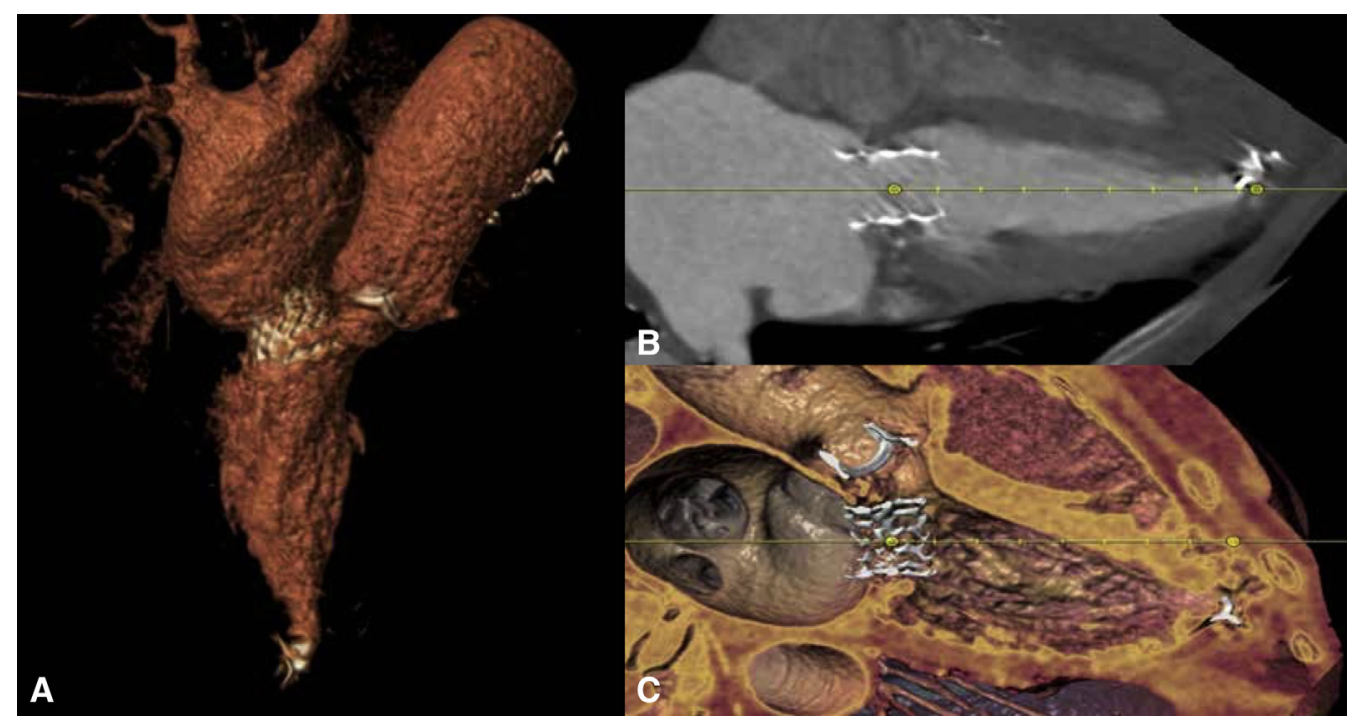

FIGURE 2. CT imaging at 1 month follow-up reveals successful LV pseudoaneurysm closure using an Amplatzer (Abbott, Minneapolis, Minn) atrial septal device and mitral valve-in-valve (A, B). CT confirms closure of LV pseudoaneurysm. C, Edwards Sapien 3 (Edwards Lifesciences, Irvine, Calif) transcatheter valve-in-valve with good position in the prior surgical mitral valve.

demonstrate its efficacy as a potential salvage for high-risk patients with mitral structural degeneration and LV injury.

\section{References}

1. Rodès-Cabau J, Kalavrouziotis D. Transcatheter mitral valve-in-valve replacement: the new gold standard for treating mitral bioprosthesis failure? JACC Cardiovasc Interv. 2018;11:1139-41.

2. Ikegami H, McCarthy PM. Internal repair of left ventricular pseudoaneurysm late after mitral valve replacement. Interact Cardiovasc Thorac Surg. 2014;18:128-30.
3. Yoon S-H, Whisenant B, Bleiziffer S, Delgado V, Schofer N Eschenbach L, et al. Transcatheter mitral valve replacement for degenerated bioprosthetic valves and failed annuloplasty rings. J Am Coll Cardiol. 2017; 70:1121-31

4. Okuyama K, Chakravarty T, Makkar R. Percutaneous transapical pseudoaneurysm closure following transcatheter aortic valve replacement. Cathet Cardiovasc Intervent. 2016;91:159-64.

5. Kumar PV, Alli O, Bjarnason H, Hagler DJ, Sundt TM, Rihal CS. Percutaneous therapeutic approaches to closure of cardiac pseudoaneurysms. Cathet Cardiovasc Intervent. 2012;80:687-99. 